\title{
Construcció d'un vehicle seguidor de línia
}

Roman Gutiérrez i Tormo

IES La Romànica, Barberà del Vallès

rgutie25@xtec.cat

Es tracta de dissenyar i construir un vehicle seguidor de línia no programable, capaç de detectar una línia negra pintada al terra i seguir-la tot sol. Es tracta d'un treball que pot ser realitzat tant a $4 t$ d'ESO com a Batxillerat en funció del grau de complexitat del disseny pel qual ens decidim (que sigui programable o no...)

Paraules clau: tecnologia, vehicle seguidor de línia, electrònica

\section{Objectius}

- Fomentar el treball en grup i la cooperació entre alumnes.

- Utilitzar correctament simuladors elèctrics i treure'ls rendiment.
- Aprendre a fabricar una placa de circuit imprès (PCB) i a soldar-hi els components necessaris.

- Posar en pràctica els continguts teòrics sobre electricitat i electrònica apresos a classe.

- Valorar la importància dels circuits elèctrics i electrònics a la societat actual.

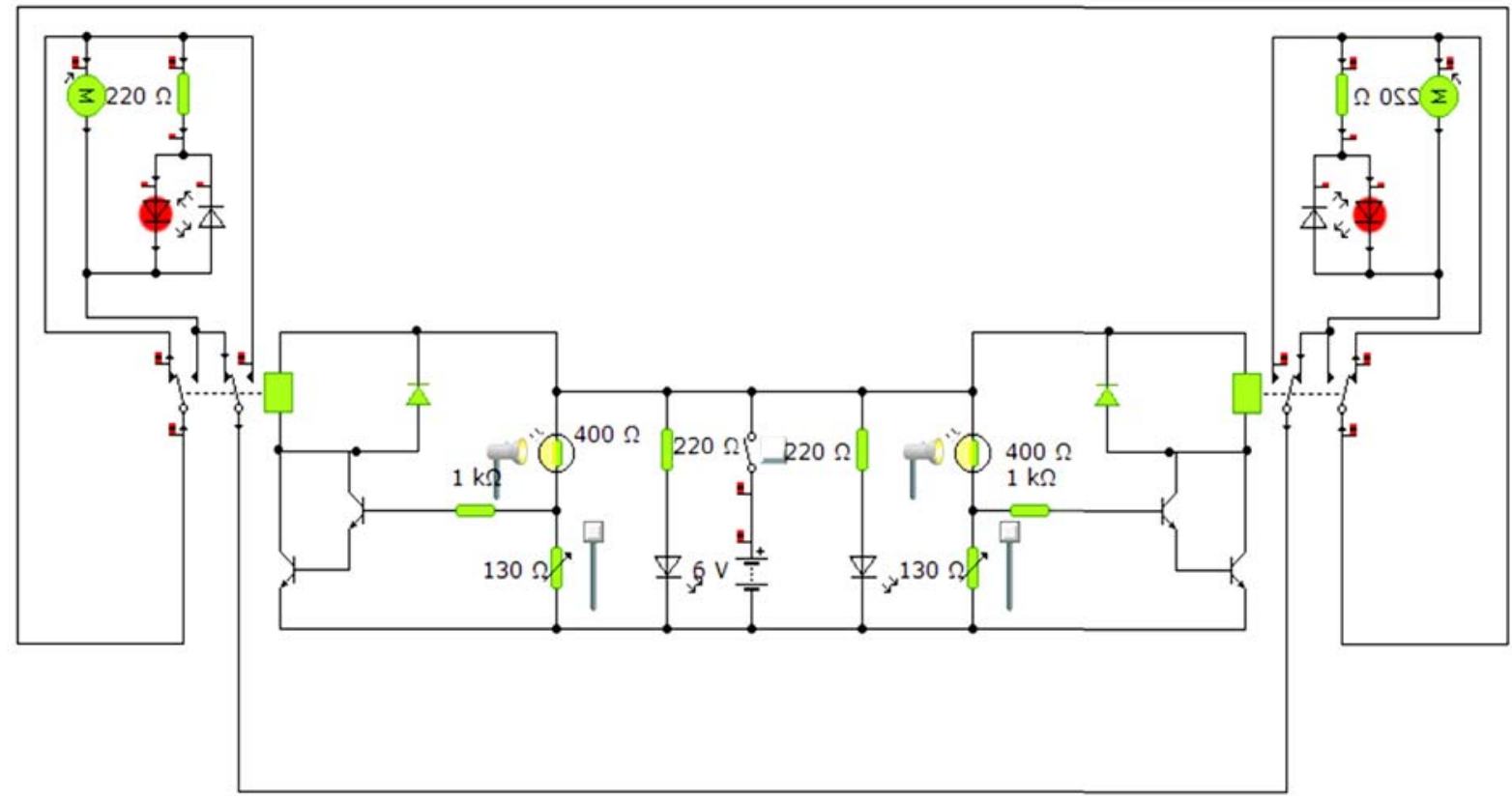

Figura 1. Circuit del vehicle seguidor de línia. 


\section{Material necessari}

- 1 Placa verge de fibra de vidre d'una sola cara de coure de $100 \times 120 \mathrm{~mm}$

- 2 Resistències LDR

- 2 Díodes d'alta lluminositat

- 4 Transistors BD135

- 2 Resistències d'1 $\mathrm{K} \Omega$

- 4 Resistències de $220 \Omega$

- 2 Potenciòmetres de $150 \mathrm{~K} \Omega$

- 2 Relés de doble contacte de $6 \mathrm{~V}$

- 2 Díodes 1N4007

- Estany

- 7 Clemes (regleta) dobles per a circuit imprès

- 2 Interruptors

- 4 Díodes LED

- 2 Portapiles

- 8 Piles $(1,5 \mathrm{~V})$

- 2 Motors amb reductora

- 2 Rodes

- 1 Roda boja

- 1 Pot de clorur de ferro(III)

- Altres: guants de làtex, recipient resistent als àcids, pinces de plàstic...

\section{Procés de disseny de la PCB}

Abans de fer servir el simulador dissenyarem sobre el paper el nostre propi circuit. Aquest primer disseny pot ser de creació pròpia o bé adaptat a partir d'algun circuit ja existent d'entre la gran quantitat de circuits predissenyats que podem trobar a llibres i pàgines web especialitzades. En el nostre cas hem dissenyat el circuit de la fig. 1.

Un cop que tenim clar com serà el nostre circuit farem servir un programa de simulació, en el nostre cas el Crocodile Technology 3D. No obstant això, podem fer servir qualsevol programa d'entre el gran ventall que hi ha al nostre abast. A més a més, hi ha diverses opcions: podem fer servir programari gratuït, programari d'avaluació $\mathrm{o}$ amb llicències educatives.

Generalment, els programes de disseny i simulació de circuits són bastant intuïtius (fig. 2). En aquest cas hem de diferenciar tres zones ben clares: l'àrea de Disseny 3D, l'àrea de Disseny 2D, i l'àrea de Components o Biblioteca.

El primer que hem de fer al programari és seleccionar les dimensions de la nostra PCB; no obstant, si al llarg del procés de disseny veieu que la grandària de placa escollida és massa petit o massa gran, sempre podem tornar-lo a modificar des de l'opció de propietats. En el nostre cas la grandària escollida per a la nostra PCB és de $100 \times 160$ $\mathrm{mm}$.

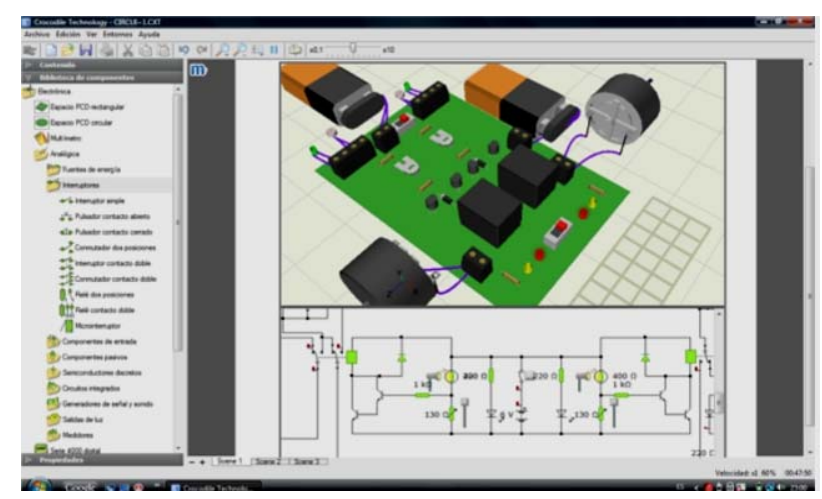

Figura 2. Captura del programari Crocodile Technology.

Un cop escollit, ens limitarem a representar en 2D a l'ordinador el circuit que prèviament havíem dissenyat sobre el paper. Per fer-ho, només cal escollir els components que necessitem de la Biblioteca de Components -que en aquest cas tenim a l'esquerra de la pantalla- $\mathrm{i}$ arrossegar-los a la finestra de disseny 2D. Un cop situats i ordenats els nostres components només hem d'enllaçar-los entre si mitjançant clics de ratolí per fer-hi aparèixer el cable.

Arribats en aquest punt tindrem el nostre circuit dissenyat en 2D i podrem passar a fer-lo en 3D. No obstant això hem de recordar que som davant d'un programari de simulació i que, per tant, abans de seguir podrem engegar el nostre circuit i comprovar si funciona correctament: si no ho fa, serà el moment de fer les modificacions pertinents.

Si tot ha sortit bé podrem passar a comprovar que mentre nosaltres hem anat inserint els components necessaris a la finestra de disseny en $2 \mathrm{D}$, a la finestra de disseny en 3D han anat apareixent els mateixos components. Així doncs, per acabar amb el nostre disseny PCB només ens quedarà arrossegar un per un tots els components $3 \mathrm{D}$ sobre la placa i situar-los al lloc on desitgem instal-lar-los. Evidentment hem de tenir en compte que elements com ara motors elèctrics i piles els arrossegarem fora de la placa, ja que no van instal-lats sobre la PCB. Al fer-los fora veurem com per a cada component apareix una connexió per unir la placa amb aquests elements externs.

Amb els components ja distribuïts per la superfície de la placa només ens queda realitzar les pistes de coure del nostre disseny. Per a això només cal que cliquem la icona de generar pistes i es generaran automàticament. Abans, però, ens sortirà un menú on podrem escollir si les volem generar de forma automàtica $o$ indicant-ne algunes preferències. 
En el moment de generar les pistes hem de tenir present que si no és possible fer totes les connexions entre components mitjançant pistes, el programa ens avisarà i realitzarà tants ponts com siguin necessaris mitjançant cable. Així doncs, si no desitgem que apareguin ponts, l'únic que hem de fer es reordenar de nou els components 3D sobre la placa, tornar a fer clic a la icona de generar pistes i creuar els dits. Si tornen a sortir ponts repetirem el procés tants cops com sigui necessari per eliminar-los. Evidentment, l'aparició de ponts és proporcional a la complexitat del circuit, i hi haurà casos que no podrem evitar la seva aparició.

\section{Procés de fabricació de la PCB}

\section{Traçat de la placa}

A pesar de qui hi ha més d'una possibilitat a l'hora de fabricar la nostra placa, anem a veure la que segons l'experiència realitzada, ens pareix més apropiada per realitzar-la a una aula/taller d'un institut.

El primer que hem de fer és imprimir el circuit que hem realitzat amb el nostre simulador per poder-lo copiar sobre la placa. Per aconseguir imprimir el nostre circuit en escala real, hi ha que exportar l'arxiu com a "Lista de nodos de Real PCB", guardar l'arxiu creat, executar-lo i imprimir-lo amb les opcions que desitgem.

Un cop tenim el full del circuit ja imprès, podem passar a copiar-lo sobre la nostra placa PCB. El primer que farem serà marcar els nodes sobre la placa, per això situarem el full que acabem d'imprimir sobre ella i a continuació passarem a marcar la situació dels nodes, podem fer servir un petit clau i un martell. Cal tenir present que no es tracta de fer un forat per instal-lar els components sinó simplement marcar la situació dels nodes, per aquest motiu anirem amb compte per aconseguir fer la marca sense foradar la placa, ja que ens pot portar problemes després en el moment del bany el clorur de ferro(III) pot introduir-se pels forats i atacar més coure del desitjat.

Un cop tenim els nodes marcats i per evitar tenir la superfície de la placa bruta, farem una neteja de la superfície de la placa amb alcohol i cotó. Aquest pas és imprescindible per aconseguir una bona qualitat de l'atac del clorur de ferro(III), ja que la brutícia o les mateixes empremtes que podem deixar amb els dits poden alterar el transcurs de l'atac. Es per això que a partir d'aquest punt farem servir guants, guants que no ens treure'm fins a finalitzar el procés d'atac.

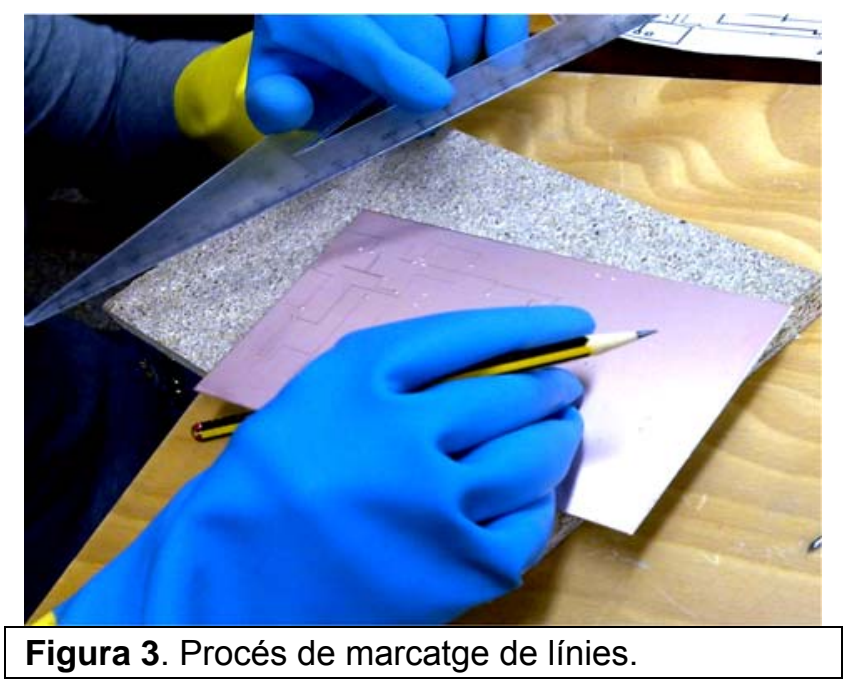

Amb la superfície de la placa ben neta realitzarem el traçat de les pistes que uniran els nodes. Recomanem de fer-ho primer amb llapis (fig. 3) i un cop ens assegurem que totes les unions són correctes podrem fer servir un retolador permanent de $1 \mathrm{~mm}$ de diàmetre.

Aquest és un dels punts més crítics de la fabricació de la placa i per tant ens assegurarem que els nodes i les línies quedin ben marcades. Els nodes han de tenir una grandària considerable ja que així conservarem més quantitat de coure al voltant dels terminals dels components un cop soldats: per això serem generosos al retolar els nodes amb el permanent. Recomanem fer dues o tres passades per pista amb el retolador permanent per crear una capa de pintura suficientment gruixuda que protegeixi el coure de l'atac del clorur de ferro(III).

\section{Atac amb clorur de ferro(III)}

A continuació, amb totes les línies de la placa marcades, passarem a fer el bany de la placa per eliminar el coure sobrant i deixar-hi únicament el que queda protegit per les capes de retolador permanent.

El bany pot realitzar-se amb diversos productes, com ara una barreja de salfumant i aigua oxigenada de 100 volums. Però en el nostre cas farem servir un preparat de clorur de ferro(III). El motiu és ben senzill: estem treballant amb alumnes d'entre 15 i 17 anys, i aquest preparat és menys agressiu que altres productes i a més pràcticament no desprèn vapors tòxics durant la realització del bany de la placa. Tot i això, no deixa de ser perillós. És per això que continuarem fent servir els guants, ens protegirem els ulls i realitzarem el bany sota l'atenta supervisió del professor i en una sala ben ventilada. 


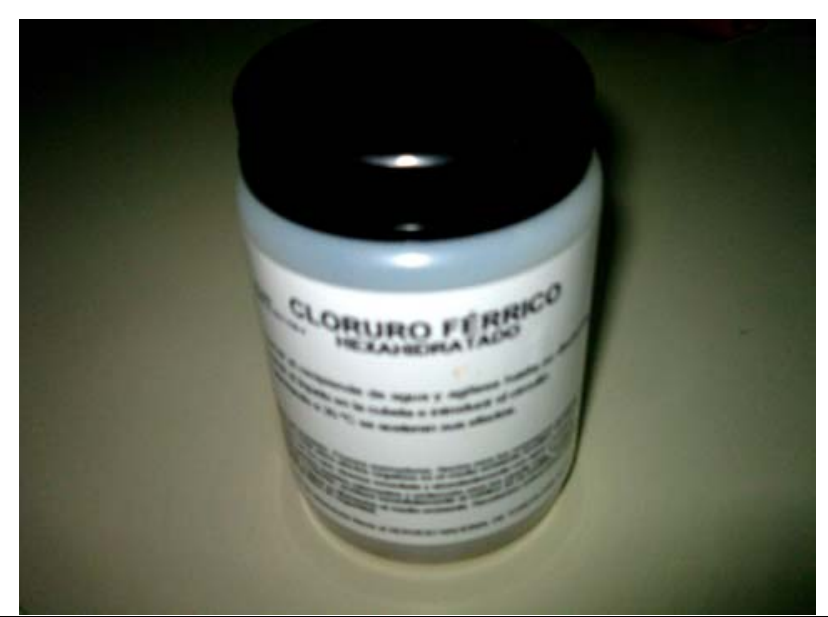

Figura 4. Clorur de ferro(III).

Per no tenir problemes amb les proporcions entre aigua i clorur de ferro(III) recomanem fer servir uns envasos de preparat que venen a les botigues especialitzades (fig. 4). Es tracta d'un pot amb un pes de $200 \mathrm{~g}$ però amb només $100 \mathrm{~g}$ de clorur de ferro(III) en estat sòlid, de forma que per obtenir la dissolució perfecta l'únic que cal fer és acabar d'emplenar aquest envàs amb aigua, tancar-lo i agitar-lo enèrgicament.

Abocarem la dissolució preparada a un recipient resistent als àcids i hi introduirem la placa amb molt de compte per no esquitxar ningú.

Per accelerar l'atac recomanem utilitzar aigua a uns $35^{\circ} \mathrm{C}$ i remenar la dissolució durant tot el procés (figs. 5 i 6 ). Segons la nostra experiència, és important tenir present que amb un únic pot podem revelar perfectament dues plaques de $100 \times 160$ $\mathrm{mm}$ i no només una, com afirmen alguns dels venedors del producte.

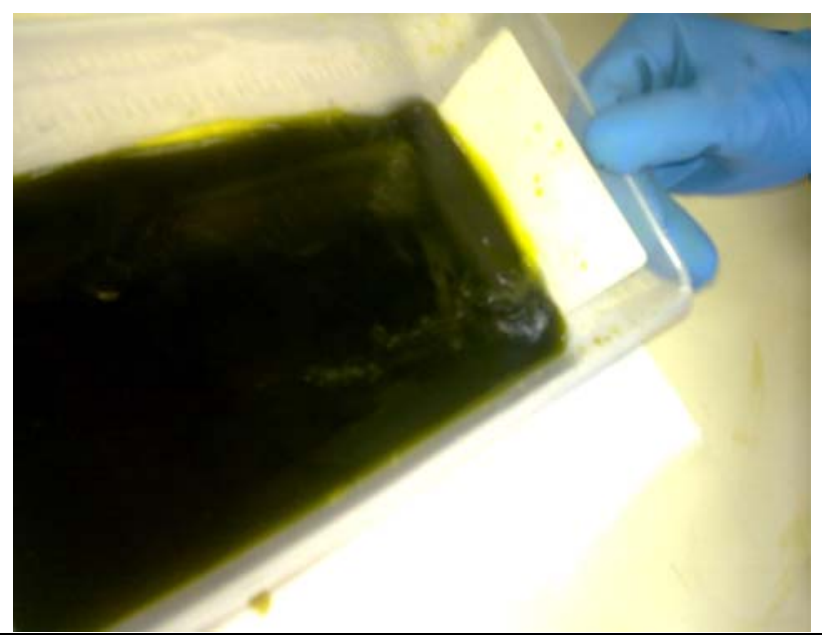

Figura 5. Bany de la placa amb clorur de ferro(III).

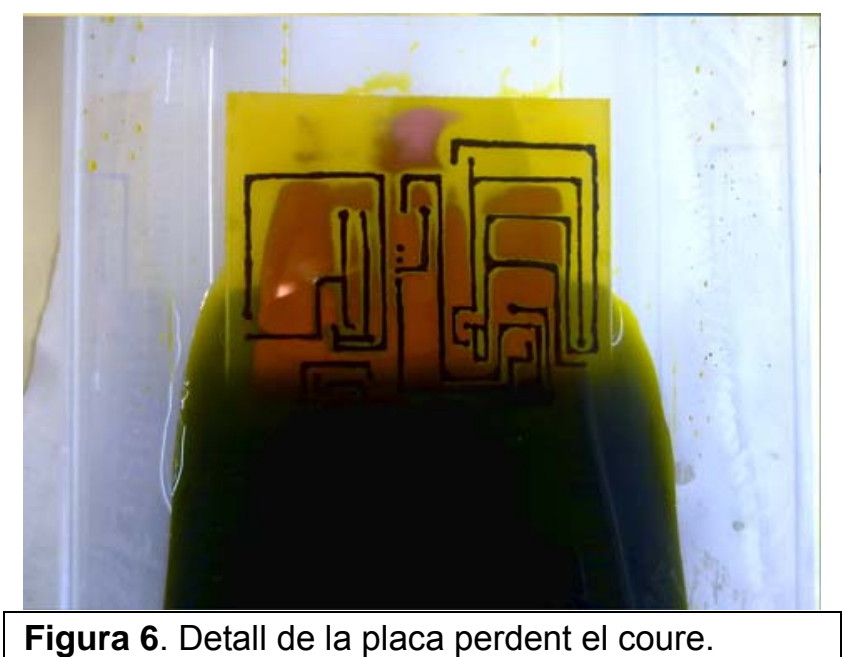

A continuació, amb uns pinces de plàstic anirem comprovant l'estat de la placa. Un cop que la placa ha perdut tot el coure sobrant podem treure-la amb molt de compte i rentar-la amb aigua abundant fins a eliminar del tot el clorur de ferro(III). Amb la placa rentada i eixuta eliminarem les línies del retolador permanent amb alcohol, deixant a la vista les pistes de coure.

Un cop acabat el bany recomanem tornar a introduir la dissolució de clorur de ferro(III) a l'envàs original per guardar-la de forma segura i portar-la a un punt blau de tractament de residus, ja que si la llencem per la pica, podem fer malbé la instal-lació del desguàs.

Per acabar la fabricació de la PCB utilitzarem un trepant amb una broca d'1 $\mathrm{mm}$ de diàmetre per foradar els nodes, on hi introduirem els terminals dels components.

En el nostre cas, a més a més realitzarem quatre forats amb una broca de $4 \mathrm{~mm}$ als cantons de la placa per poder collar la placa al suport que farem servir de xassís del vehicle.

\section{Soldadura dels components}

Obtinguda la nostra placa PCB, ha arribat el moment de realitzar-hi les soldadures.

Per realitzar la soldadura correctament realitzarem els següents passos per a cada component a soldar (figs. 7 i 8 ):

1) Introduir el component correctament al seu lloc. Pararem especial atenció als components amb polaritat (condensadors, transistors...)

2) Una vegada introduïts els components cal escalfar el terminal amb la punta del soldador. 
3) Amb el terminal escalfat, i sense retirar la punta del soldador aproparem el fil d'estany per fondre'l i aconseguir el contacte entre la pista corresponent i el terminal.

4) A continuació retirarem el fil l'estany.

5) I finalment retirarem la punta del soldador.

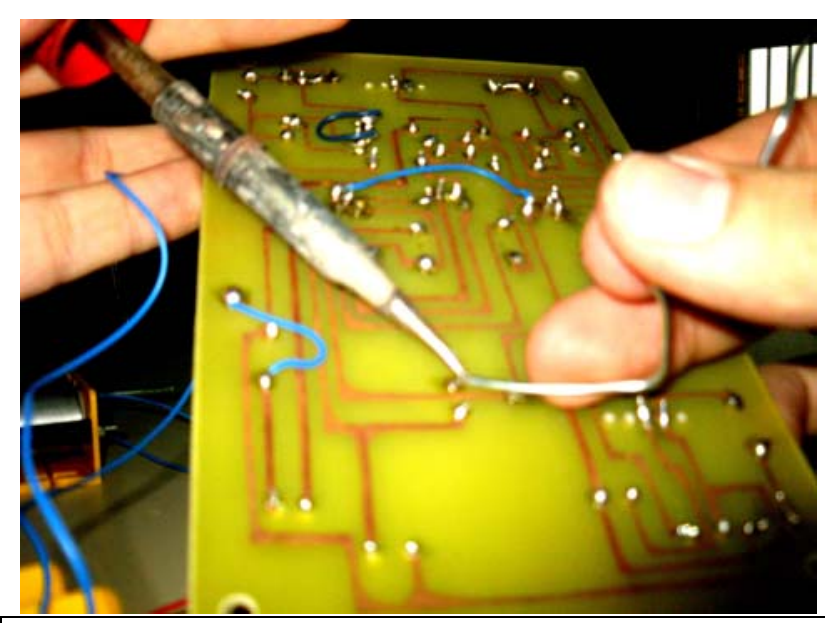

Figura 7. Detall de la soldadura.

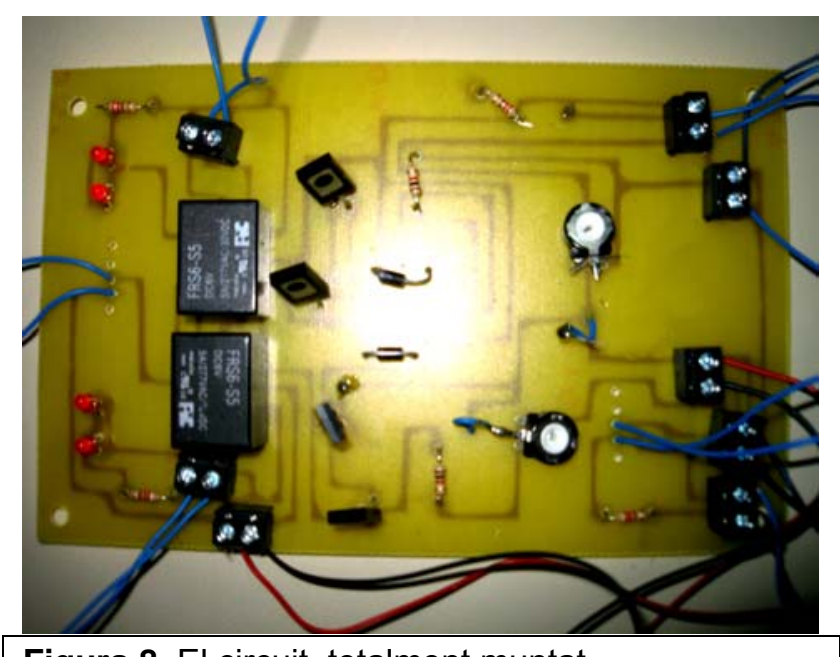

Figura 8. El circuit, totalment muntat.

Consells per a la soldadura:

- Eviteu el contacte entre la punta del soldador amb la placa o qualsevol part plàstica dels components a soldar, ja que evidentment al tractarse de plàstic es fondrà i podríem fer malbé la placa i els components.
- Evitarem també d'escalfar en excés els terminals dels components ja que un excés de temperatura pot acabar espatllant internament els components.

\section{Muntatge del cotxe}

Aquest apartat és el més obert de tots, ja que amb la placa ja acabada ara cadascú pot modificar la forma i els colors externs del vehicle al seu gust.

Els passos a seguir seran situar la placa PCB amb els components collada al xassís, instal lar els dos motors amb les seves rodes, la roda boja i les bateries.

Per deixar-ho tot enllestit només queda assegurar-nos que el díode d'alta lluminositat està prou baix per reflectir la seva llum sobre el terra, i que el sensor LDR és suficientment prop de terra per notar la variació de reflexió de la llum sobre el fons blanc i la línia negra del terra.

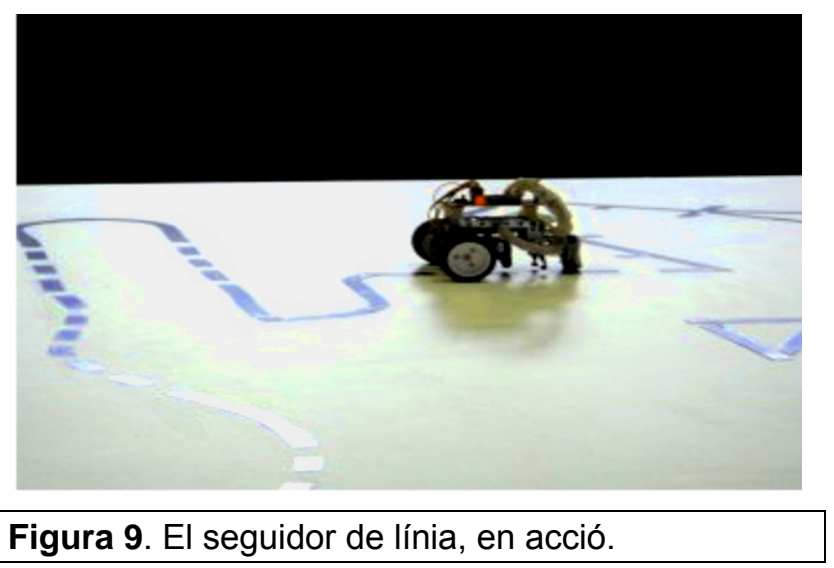

\section{Valoració}

La construcció del vehicle seguidor de línia ha estat una experiència meravellosa. Després de realitzar aquesta experiència, la recomano al $100 \%$. Es tracta d'un projecte molt maco des del punt de vista del professor, però molt més encara des del punt de vista de l'alumnat, que només desitjava que arribés l'hora de tecnologia per posar-se a muntar el seu vehicle. Es tracta d'un projecte que permet aprofitar l'entusiasme de l'alumnat per aconseguir que experimenti amb el món de l'electrònica però, a més a més, aconseguim afavorir la comprensió dels continguts teòrics per la seva part, que sempre és d'agrair. 